\title{
Mechanical load on the inspiratory muscles during exercise hyperpnea in patients with Type 1 (insulin-dependent) diabetes mellitus
}

\author{
T. Wanke ${ }^{1}$, D. Formanek ${ }^{1}$, M. Auinger ${ }^{2}$, M. Merkle ${ }^{1}$, H.Lahrmann ${ }^{3}$, H.Zwick ${ }^{1}$ and K. Irsigler $^{2}$ \\ ${ }^{1}$ Pulmonary Department, ${ }^{2} 3^{\text {rd }}$ Metabolic Department and L. Boltzmann-Research-Institute for Metabolic Diseases and Nutrition, \\ Lainz Hospital, and ${ }^{3}$ Department of Physics, Technical University, Vienna, Austria
}

\begin{abstract}
Summary. The aim of this study was to evaluate the difference between Type 1 (insulin-dependent) diabetic patients and healthy control subjects regarding inspiratory muscle load during exercise hyperpnea. For this purpose an incremental progressive exercise test on a cycle ergometer was performed by 36 Type 1 diabetic patients and 40 healthy subjects. In order to determine the mechanical load on the inspiratory muscles breath by breath, we selected the following two parameters, which represent the pressure generated by the inspiratory muscles as well as the duration and velocity of their contraction: (1) the oesophageal tension time index, which is the product of the duty cycle (ratio of inspiratory time to total breath cycle duration) and the mean oesophageal pressure expressed as a percentage of the maximal oesophageal pressure and (2) the mean oesophageal pressure change per time unit during the inspiratory phase of
\end{abstract}

each breathing manoeuver, which is expressed as a fraction of the subject's maximal oesophageal pressure. Comparison of the two groups revealed that at similar levels of ventilation the mechanical load on the inspiratory muscles was significantly higher in the Type 1 diabetic patients than in the control subjects. When the loading was stopped the maximal ventilation was lower in the patients. Nevertheless, they reported a degree of respiratory effort sensation comparable to the control group, which seems to have been caused by an increase of the mechanical load on the ventilatory muscles.

Key words: Inspiratory muscle load, cycle ergometer test, diabetes mellitus, exercise hyperpnea, respiratory effort sensation.
In the last decade studies investigating lung mechanics in Type 1 (insulin-dependent) diabetic patients have demonstrated pathological changes in lung function indices [1-3]. Recently inspiratory muscle weakness was reported to have an impact on reduced lung volumes in diabetic patients [4]. The performance of the inspiratory muscles is highly responsible for the intensity with which this group of muscles is employed, both at rest and during exercise, in each breathing manoeuver. Up to now there have not been any data available concerning the mechanical load on the inspiratory muscles of diabetic patients during rest and exercise. Our principal aim, therefore, was to analyse the inspiratory muscle load of Type 1 diabetic patients during an incremental cycle ergometer test in comparison to healthy control subjects. Thereby the parameters expressing the mechanical load on the inspiratory muscles should reflect the factors that account for the energy consumption of this group of muscles: (1) the tension developed, (2) the velocity of contraction and (3) the duration of contraction [5].

\section{Subjects and methods}

The study included 36 Type 1 diabetic patients ( 31 male, 5 female). Selection criteria consisted of (1) insulin dependence from the time of diagnosis; (2) age at onset below 30 years; (3) regular attendance at the Diabetic Department of our hospital; (4) no hospital admissions during the previous 6 months; (5) absence of obesity (body mass index $<30 \mathrm{~kg} / \mathrm{m}^{2}$ ) and (6) absence of clinical or radiological cardiorespiratory abnormalities. Another criteria demanded that serum creatinine concentrations be within the normal range $(<106 \mu \mathrm{mol} / \mathrm{l})$. Two patients had a slight proteinuria and six patients microalbuminuria. Autonomic function was evaluated according to the protocol of Ewing and Clarke [6]. This involved the measurement of heart-rate response to postural changes and deep breathing, as well as the blood pressure response to postural changes. Five patients had at least two abnormal parasympathetic (heart-rate) responses. All patients had normal orthostatic blood pressure responses ( 1 min after standing up the decrease in systolic blood pressure was less than $15 \mathrm{~mm} \mathrm{Hg}$ ). Ophthalmoscopy, performed by an experienced ophthalmologist immediately before the exercise experiments showed that none of the patients had a high risk of retinal haemorrhage. 


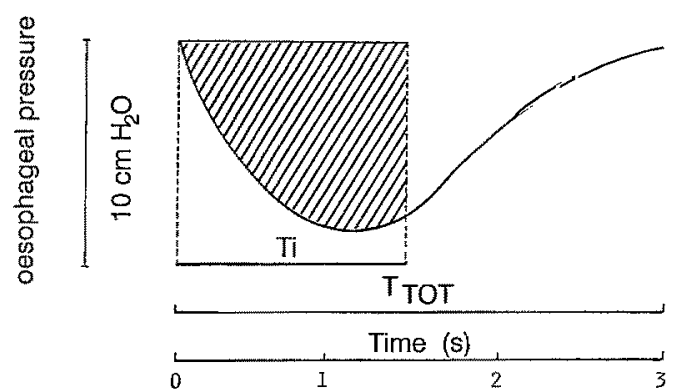

Fig. 1. The shaded area delimited by the oesophageal pressure trace and inspiratory time $\left(\mathrm{T}_{1}\right)$ was measured and expressed as a fraction of maximum oesophageal pressure and total breath cycle duration $\left(\mathrm{T}_{\mathrm{T} \text { TOR }}\right)$

\section{0 沗 MAXIMUM \\ 9 VERY VERY SEVERE \\ 8 \\ 7 VERY SEVERE \\ 6 青

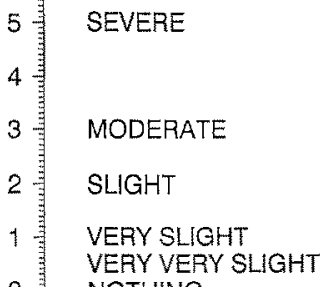 NOTHING}

Fig.2. Modified Borg scale for estimation of breathlessness out, starting with 2 min of unloaded cycling and gradually increasing the performance by $25 \mathrm{~W}$ every $2 \mathrm{~min}$. For determining the oesophageal tension time index we used a method described previously [13]. Thereby oesophageal pressures were continuously plotted against time breath by breath by the Beckman strip-chart recorder that drew the pressure curves parallel to the inspiratory and expiratory flow tracings. The end-expiratory pressure values of each breath were arbitrarily considered zero. At least eight breathing cycles from each stage of load increment (two breathing cycles per $30 \mathrm{~s}$ ) were chosen for evaluating the time integral of the oesophageal pressure. These pressure-time curves were enlarged by photomechanical means and manually digitised. The oesophageal pressure time-integral was calculated for each area delimited by the oesophageal pressure trace and the inspiratory time axis. It was expressed as a fraction of the subject's maximum oesophageal pressure ( $\left(\mathrm{Pes}_{\max }\right)$ and the total breath cycle duration $\left(T_{t o t}\right)$. This parameter was termed the oesophageal tension time index: $\mathrm{TTI}_{\mathrm{es}}=\left({ }_{\mathrm{o}}{ }^{\mathrm{T}} \mathrm{Pes} \cdot \mathrm{dT}_{\mathrm{i}}\right) /\left(\mathrm{Pes}_{\mathrm{max}} \cdot \mathrm{T}_{\text {tot }}\right)($ Fig. 1$)$. The pressuretime curves were also used to compute the mean change of the oesophageal pressure with respect to time during inspiration, with the oesophageal pressure being expressed as a percentage of $P$ es ${ }_{\max }$ :

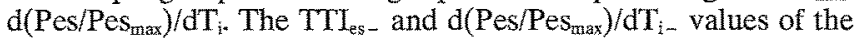
diabetic patients were compared with those of the healthy control subjects at various levels of minute ventilation expressed as a percentage of maximal voluntary ventilation (MVV): $10,20,30,40$, and $50 \%$ MVV.At each stage of loading the subjects had to mark the points on a ten-point modified Borg scale [14] that best corresponded to the respiratory effort sensation they had perceived individually (Fig. 2).

Samples of capillary blood drawn from the finger of the diabetic patients were used to determine the glucose concentrations before and after the exercise test with a Beckman glucose analyser (model Glucose-Analyser 2, Beckman).

Each subject signed an informed consent for the experimental protocol which was approved by the ethical review committee of the hospital.

\section{Statistical analysis}

Differences between groups were estimated by the two-tailed $t$-test. F-test was used to prove homogenity (homoscedasticity) of variances: $s x^{2}=s y^{2}$ (i. e. F value had to be near 1 ) and was a precondition for the applicability of the $t$-test. Values in the text and tables are presented as means $\pm \mathrm{SD}, p<0.05$ was accepted as statistically significant. Correlation coefficients (one-way ANOVA) were used to assess an association between inspiratory muscle load and various disease characteristics (such as duration of diabetes, the presence of autonomic neuropathy or microalbuminuria).

\section{Results}

There was no significant difference in anthropometric data between the diabetic patients and the control subjects (Table 1). Among the diabetic patients, the mean duration of disease was $14.2 \pm 8.3$ years. The mean $\pm S D$ values of all pulmonary function and inspiratory muscle performance

Table 1. Physical characteristics of diabetic patients and control subjects

\begin{tabular}{lccl}
\hline & $\begin{array}{l}\text { Type 1 } \\
\text { (insulin-dependent) } \\
\text { diabetic patients } \\
\text { Mean } \pm \text { SD }\end{array}$ & $\begin{array}{l}\text { Control } \\
\text { Subjects } \\
\text { Mean } \pm \text { SD }\end{array}$ & $\begin{array}{l}\text { Significance } \\
\text { of } \\
\text { differences }\end{array}$ \\
\hline Age (years) & $33 \pm 12$ & $27 \pm 11$ & NS \\
Height $(\mathrm{cm})$ & $176.6 \pm 8.4$ & $178.1 \pm 10.3$ & NS \\
Weight $(\mathrm{kg})$ & $76.0 \pm 11.8$ & $71.0 \pm 12.9$ & NS \\
BMI $\left(\mathrm{kg} / \mathrm{m}^{2}\right)$ & $24.3 \pm 3.1$ & $22.3 \pm 2.7$ & NS \\
\hline
\end{tabular}

BMI, Body mass index 
Table 2. Lung function parameters and inspiratory muscle performance of diabetic patients and control subjects

\begin{tabular}{|c|c|c|c|}
\hline & $\begin{array}{l}\text { Type } 1 \\
\text { (insulin-dependent) } \\
\text { diabetic patients } \\
\text { Mean } \pm \text { SD }\end{array}$ & $\begin{array}{l}\text { Control } \\
\text { Subjects } \\
\text { Mean } \pm \text { SD }\end{array}$ & $\begin{array}{l}p \\
\text { value }\end{array}$ \\
\hline $\mathrm{VC}_{\mathrm{in}}(\mathrm{l})$ & $4.75 \pm 0.84$ & $5.36 \pm 1.37$ & $<0.01$ \\
\hline $\mathrm{FEV}_{1}(\mathrm{l})$ & $3.8 \pm 0.7$ & $4.3 \pm 1.1$ & $<0.05$ \\
\hline $\mathrm{FEV}_{1} \% \mathrm{VC}_{\mathrm{in}}(\%)$ & $79.4 \pm 4.7$ & $80.3 \pm 4.3$ & NS \\
\hline TLC (1) & $7.1 \pm 1.5$ & $7.9 \pm 1.8$ & NS \\
\hline FRC (l) & $4.3 \pm 1.3$ & $4.5 \pm 1.1$ & NS \\
\hline RV (l) & $2.4 \pm 0.8$ & $2.6 \pm 0.6$ & NS \\
\hline $\mathrm{C}_{\mathrm{spec}}\left(1 \cdot \mathrm{cm} \mathrm{H} \mathrm{H}_{2} \mathrm{O}^{-1} \cdot \mathrm{l}\right)$ & $0.06 \pm 0.019$ & $0.072 \pm 0.02$ & NS \\
\hline $\mathrm{R}_{\mathrm{tot}}\left(\mathrm{kPa} \cdot 1^{-1} \cdot \mathrm{s}\right)$ & $0.16 \pm 0.06$ & $0.18 \pm 0.07$ & NS \\
\hline $\mathrm{MVV}\left(1 \cdot \min ^{-1}\right)$ & $153.2 \pm 35.1$ & $167.2 \pm 50.6$ & $<0.05$ \\
\hline $\mathrm{Pes}_{\max }\left(\mathrm{cm} \mathrm{H} \mathrm{H}_{2} \mathrm{O}\right)$ & $74.7 \pm 20.9$ & $95.8 \pm 33.5$ & $<0.05$ \\
\hline
\end{tabular}

$\mathrm{VC}_{\mathrm{n}}$, inspiratory vital capacity; $\mathrm{FEV}_{1}$, forced expired volume in $1 \mathrm{~s}$; TLC, total lung capacity; FRC, functional residual capacity; RV, residual volume; $C_{\text {spec }}$ specificlung compliance; $R_{\text {tot }}$, airway resistance; MVV, maximal voluntary ventilation; $\mathrm{Pes}_{\max }$, maximal sniff generated oesophageal pressure

Table 3. Minute ventilation at end-exercise

\begin{tabular}{lccc}
\hline & $\begin{array}{l}\text { Type } 1 \\
\text { (insulin-dependent) } \\
\text { diabetic patients } \\
\text { Mean } \pm \mathrm{SD}\end{array}$ & $\begin{array}{l}\text { Control } \\
\text { Subjects } \\
\text { Mean } \pm \mathrm{SD}\end{array}$ & $\begin{array}{l}p \\
\text { value }\end{array}$ \\
& $84.6 \pm 25$ & $115.2 \pm 31.2$ & $<0.01$ \\
$\mathrm{VE}_{\max }(1 / \min )$ & $56 \pm 14$ & $70 \pm 18$ & $<0.01$ \\
$\mathrm{VE}_{\max }(\mathrm{MVV} \times 100$ & $186 \pm 52$ & $233 \pm 48$ & $<0.05$ \\
$\mathrm{~W}_{\max }(\mathrm{W})$ & &
\end{tabular}

$\mathrm{VE}_{\max }$, maximal ventilation; MVV, maximal voluntary ventilation; $\mathrm{W}_{\max }$, maximal work capacity

Table 4. Parameters determining the mechanical load on the ventilatory muscles at different levels of $\mathrm{VE} \% \mathrm{MVV}^{\mathrm{a}}$

\begin{tabular}{lcccc}
\hline & $\begin{array}{l}\text { VE\% } \\
\text { MVV }\end{array}$ & $\begin{array}{l}\text { Type 1 } \\
\text { (insulin- } \\
\text { dependent) } \\
\text { diabetic } \\
\text { patients }\end{array}$ & $\begin{array}{l}\text { Control } \\
\text { Subjects }\end{array}$ & $\begin{array}{l}p \\
\text { value }\end{array}$ \\
& \multicolumn{5}{c}{} & \\
\hline TTIes & 10 & $0.037 \pm 0.020$ & $0.027 \pm 0.017$ & $<0.001$ \\
& 20 & $0.061 \pm 0.027$ & $0.040 \pm 0.024$ & $<0.001$ \\
& 30 & $0.082 \pm 0.034$ & $0.057 \pm 0.026$ & $<0.001$ \\
& 40 & $0.094 \pm 0.037$ & $0.067 \pm 0.029$ & $<0.001$ \\
& 50 & $0.110 \pm 0.044$ & $0.083 \pm 0.035$ & $<0.001$ \\
$\mathrm{~d}($ Pes/Pesmax $) / \mathrm{dT}_{\mathrm{I}}$ & 10 & $0.11 \pm 0.08$ & $0.08 \pm 0.03$ & $<0.001$ \\
& 20 & $0.20 \pm 0.09$ & $0.13 \pm 0.06$ & $<0.001$ \\
& 30 & $0.28 \pm 0.10$ & $0.22 \pm 0.11$ & $<0.001$ \\
& 40 & $0.37 \pm 0.14$ & $0.32 \pm 0.16$ & $<0.01$ \\
& 50 & $0.45 \pm 0.08$ & $0.45 \pm 0.21$ & NS \\
\hline
\end{tabular}

${ }^{a} \mathrm{VE} \% \mathrm{MVV}$, minute ventilation during exercise as percentage of maximal voluntary ventilation; TTIes, oesophageal tension time index; $\mathrm{d}\left(\mathrm{Pes} / \mathrm{Pes}_{\mathrm{max}}\right) / \mathrm{dT}_{\mathrm{I}}$, rate of change of oesophageal pressure (expressed as a fraction of maximum oesophageal pressure) with respect to time

parameters in the diabetic patients and the control subjects are given in Table 2 . In accordance with the literature [15, 16], highly significant differences were found in inspiratory vital capacity $\left(\mathrm{VC}_{\mathrm{in}}\right)$, and significant differences were found in forced expiratory values in one second $\left(\mathrm{FEV}_{1}\right)$. The $\mathrm{FEV}_{1} \% \mathrm{VC}_{\mathrm{in}}$ ratio, however, was similar in the two groups, so that airflow limitation in the patient groupcan be excluded. Specific compliance was similar in the two groups. The values of maximum oesophageal pressure and the $12 \mathrm{~s}$ maximal voluntary ventilation test were significantly higher in the control group. As the endurance capacity of the inspiratory muscles was reduced in the diabetic patients, the ventilation values achieved during exercise were expressed as a percentage of the $12 \mathrm{~s}$ maximal voluntary ventilation test (VE\% MVV); thus it was possible to compare the patients with the control group at corresponding levels of ventilation. The levels of blood glucose concentration in the patients at end-exercise did not differ significantly from the values recorded at rest $(10.92 \pm$ $1.4 \mathrm{mmol} \cdot 1^{-1}$ at end-exercise vs $10.36 \pm 1.2 \mathrm{mmol} \cdot \mathrm{1}^{-1}$ at rest). At maximal loading all subjects reached a respiratory exchange ratio greater than 1.1 , which indicates exhaustive loading [17]. The mean values for minute ventilation at end-exercise expressed in $1 \cdot \mathrm{min}^{-1}$ and as a percentage of MVV, are shown in Table 3. Comparing the indices for inspiratory muscle load during exercise hyperpnea of both groups, we found highly significant differences in the $\mathrm{TTI}_{\text {es }}$ -and d(Pes/Pes $\left.s_{\max }\right) / \mathrm{dT}_{\mathrm{i}}$ values (Table 4). The TTI $\mathrm{Tes}_{\text {-values }}$ of the diabetic patients were higher at each level of VE\%MVV. Additionally, from 10 to $40 \%$ of MVV the $\mathrm{d}\left(\mathrm{Pes} / \mathrm{Pes}_{\mathrm{max}}\right) / \mathrm{dT}_{\mathrm{j}}-$ values of the patients were significantly higher, which reflects a higher muscle contraction velocity. Although $\mathrm{VE}_{\max }$, expressed in $1 \cdot \mathrm{min}^{-1}$ or as a percentage of MVV, was lowerin the patient group, the scores on the Borg scale were identical in the two groups ( $6.8 \pm 1$ vs $6.6 \pm$ 0.8 units).

The correlation between the two parameters for inspiratory muscle load and various disease characteristics did not offer a significant trend that the presence of any parameter could be associated with higher muscle load.

\section{Discussion}

The mechanical load on the inspiratory muscles, as on other skeletal muscles, has both a force and a velocity component $[5,18]$. The force component is reflected in the tension-time index that relates muscle contraction intensity and duration to the maximal ability to generate pressure. The velocity component is reflected in the d(Pes/ $\left.\mathrm{Pes}_{\max }\right) / \mathrm{dT}_{\mathrm{i}}$ - ratio, i. e. the mean pressure change per time unit during inspiration expressed as a fraction of the maximal inspiratory pressure. Both indices have been shown to correlate with muscle oxygen demand [19-21]. The $\mathrm{TTI}_{\mathrm{es}}$ - as well as the $\mathrm{d}\left(\mathrm{Pes} / \mathrm{Pes}_{\max }\right) / \mathrm{dT}_{\mathrm{i}}$ - values can be increased by any combination of increased resistance, decreased compliance and inspiratory muscle weakness. Airway resistance was found to be similar in the diabetic patients as well as the control subjects.

Although the inspiratory vital capacities and the values of forced expiratory volume in $1 \mathrm{~s}$ were found to be reduced, the present investigation has shown that in patients with Type 1 diabetes the data of specific lung compliance did not significantly deviate from the normal range. These findings are neither in accordance with the results obtained by Schuyler and co-workers [3], who found a decrease in lung elastic recoil at low lung volumes, nor with Sandler and associates [22], who reported a small increase of pulmonary distensibility in diabetic patients compared 
with that in control subjects. Schernthaner, on the contrary, found no difference in specific lung compliance in diabetic patients [23], and recently it has been possible to demonstrate again that pulmonary distensibility is not pathologically altered in diabetic patients [24]. The results of our study indicate that lung elasticity does not have a major impact on the mechanical load of the inspiratory muscles in diabetic patients.

Inspiratory muscle performance was shown to be pathological in diabetic patients and, additionally, there was found a link between impaired inspiratory muscle performance and reduced lung volumes [4]. The results of our study have revealed that the parameters for the strength and endurance of the inspiratory muscles are reduced in diabetic patients. Under a given ventilation, the mechanical load on the inspiratory muscles increases if those muscles are weak. We were able to demonstrate in our study that at each level of VE\% MVV the TTI es $_{\text {-values were sig- }}$ nificantly higher in the diabetic patients. Moreover, at levels ranging from 10 to $40 \%$ of MVV the $\mathrm{d}\left(\mathrm{Pes} / \mathrm{Pes}_{\max }\right) / \mathrm{dT}_{\mathrm{i}}$ - values were significantly elevated in the patient group. These results indicate that for a given level of ventilation, expressed as percentage of MVV, the inspiratory muscles of the diabetic patients have a greater energy demand.

Although maximal ventilation at end-exercise, expressed either in $1 \cdot \min ^{-1}$ or as a fraction of MVV, was lower in the diabetic patients, all of the patients and control subjects complained about the same degree of respiratory effort sensation. Recently, in healthy subjects a close correlation could be demonstrated between inspiratory effort sensation and oesophageal pressure, expressed as a percentage of maximal oesophageal pressure [25]. Although the mechanical load on the inspiratory muscles was elevated in our diabetic patients, inspiratory effort sensation was identical in the patient group and the healthy control subjects. This fact might be due to a decreased ability to perceive inspiratory loads in diabetic patients [26].

Our findings concerning an increase of the mechanical load on the ventilatory muscles in diabetic patients during exercise will certainly have to be taken into consideration in the course of further studies about diabetic patients during exercise. Extreme physical exertion seems to cause inadequately high respiratory efforts in Type 1 diabetic patients, which leads to a reduction in performance.

Acknowledgements. The authors thank Ms. M.A. Lahrmann-Ramharter for the correction of the manuscript.

\section{References}

1. Bell D, Collier A, Matthews DM, Cooksey EJ, Mc Hardy GJR, Clarke BF (1988) Are reduced lung volumes in IDDM due to defect in connective tissue? Diabetes $37: 829-831$

2. Schnapf BM, Banks RA, Silverstein JM, Rosenbloom AL, Chresrown SE, Loughlin GM (1984) Pulmonary function in insulin-dependent diabetes mellitus with limited joint mobility. Am Rev Respir Dis 130: 930-936

3. Schuyler MR, Nicwochner DE, Inklery SR, Kohn R (1975) Abnormal lung elasticity in juvenile diabetes mellitus. Am Rev Respir Dis $113: 37-41$

4. Wanke T, Formanek D, Auinger M, Popp W, Zwick H, Irsigler K (1991) Inspiratory muscle performance and pulmonary function changes in insulin dependent diabetes mellitus. Am Rev Respir Dis 143:97-100
5. Hill AV (1964) The effect of load on the heat of shortening muscle. Proc R Soc Biol 159:297-318

6. Ewing DJ, Clarke BF (1982) Diagnosis and management of diabetic autonomic neuropathy. $\mathrm{Br}$ Med J 285: 916-918

7. Cotes JE (1979) Assessment of mechanical and bellows attitudes of the lung. In: Cotes JE (ed) Lung function assessment and application in medicine, 4th edn. Blackwell, Oxford London Edinbourgh Melbourne, pp 97-130

8. Cotes JE (1979) Structure, expansion and movement of the lung. In: Cotes JE (ed) Lung function assessment and application in medicine, 4th edn. Blackwell, Oxford London Edinbourgh Melbourne, pp 57-96

9. Aldrich TK, Arora NS, Rochester DF (1982) The influence of airway obstruction and respiratory muscle strength on maximal voluntary ventilation in lung disease. Am Rev Respir Dis 126: 195-199

10. Arora NS, Rochester DF (1982) Respiratory muscle strength and maximal voluntary ventilation in undernourished patients. Am Rev Respir Dis 126:5-8

11. Mier A, Brophy C, Moxham J, Green M (1988) Assessment of diaphragm weakness. Am Rev Respir Dis 137: 877 -883

12. Miller JM, Moxham J, Green M (1985) The maximal sniff in the assessment of diaphragm function in man. Clin Sci 69:91-96

13. Wanke T, Formanek D, Schenz G, Popp W, Gatol H, Zwick H (1991) Mechanical load on the ventilatory muscles during an incremental cycle ergometer test. Eur Respir J 4:385-392

14. Ward ME, Eidelman D, Stubbing DG, Bellemare F, Macklem PT (1988) Respiratory sensation at pattern of respiratory muscle activation during diaphragm fatigue. J Appl Physiol 65:2181-2189

15. Buckingham B, Perejda AJ, Sandborg C, Kreshnar AK, Uitto J (1986) Skin, joint and pulmonary changes in type 1 diabetes mellitus. Am J Dis Child 140: 420-423

16. Primhak RA, Whincup G, Tsanakas JN, Milner RD (1987) Reduced vital capacity in insulin dependent diabetes mellitus. Diabetes 36: 324-325

17. Jones NL (1988) Normal standards. In: Jones NL (ed) Clinical exercise testing, $3^{\text {rd }}$ edn. Saunders, Philadelphia London Toronto, pp 306-311

18. Mommaerts WFHM (1969) Energetics of muscular contraction. Physiol Rev 49: 427-508

19. Field S, Sanci S, Grassino A (1984) Respiratory muscle oxygen consumption estimated by the diaphragm pressure - time index. J Appl Physiol: Respirat Environ Exercise Physiol 57: 44-51

20. Collett PW, Perry C, Engel LA (1985) Pressure - time product, flow and oxygen cost of resistive breathing in humans. J Appl Physiol 58: 1263-1272

21. McCool FD, Mc Cann DR, Leith DE, Hoppin FG (1986) Pressure - flow effects on endurance of inspiratory muscles. J Appl Physiol 60: 299-303

22. Sandler M, Bunn AE, Stewart RI (1987) Cross-sectional study of pulmonary function in patients with insulin-dependent diabetes mellitus. Am Rev Respir Dis 135: 223-229

23. Schernthaner G, Haber P, Kummer F, Ludwig H (1977) Lung elasticity in juvenile onset diabetes mellitus. Am Rev Respir Dis 116: $544-545$

24. Maccioni FJ, Colebatch HJH (1991) Lung volume and distensibility in insulin-dependent diabetes mellitus. Am Rev Respir Dis 143: $1253-1256$

25. Bradley TD, Chartrand DA, Fitting JW, Killian KJ, Grassino A (1986) The relation of inspiratory effort sensation to fatiguing patterns of the diaphragm. Am Rev Respir Dis 134:1119-1124

26. O'Donnell CR, Friedman LS, Russomanno JH, Rose RM (1988) Diminished perception of inspiratory - resistive loads in insulindependent diabetics. N Enl J Med 319: 1369-1373

Received: 15 October 1991

and in revised form: 9 December 1991

Dr. T. Wanke, Pulmonary Department

Lainz Hospital, Wolkersbergenstrasse 1

A-1130 Vienna, Austria 